\title{
Geração de Eletricidade Abordando o Ciclo de Vida: Uma Revisão Sistemática sob a Ótica da Sustentabilidade Ambiental
}

\section{Electrical Power through Life Cycle: A Systematic Review under the Optics of Environmental Sustainability}

\author{
${ }^{1}$ Leonardo Affonso Ramos, ${ }^{2}$ Luciane Cleonice Durante, ${ }^{3}$ Ivan Julio Apolônio Callejas
}

\begin{abstract}
${ }^{1}$ Mestrando no Programa de Pós - Graduação em Engenharia de Edificações e Ambiental-PPGEA, Faculdade de Arquitetura, Engenharia e Tecnologia- FAET da Universidade Federal de Mato Grosso - UFMT (leonardoaffonsoramos@hotmail.com) ${ }^{2}$ Professora Doutora no Departamento de Arquitetura e do PPGEA- FAET/ UFMT(lucianedurante@ufmt.br) ${ }^{3}$ Professor Doutor no Departamento de Arquitetura e do PPGEA- FAET/ UFMT(ivancallejas@ufmt.br)
\end{abstract}

\begin{abstract}
RESUMO: A utilização de placas fotovoltaicas para geração de energia elétrica é citada como uma solução sustentável quando comparada com outras formas de geração, como usinas nucleares e termelétricas. A matriz energética brasileira é composta predominantemente por usinas hidrelétricas, que apesar dos impactos ambientais causados durante a fase de construção, possuem baixa emissão de gases poluentes e resíduos durante a operação, podendo também ser considerada uma solução sustentável. Este artigo tem por objetivo demonstrar a contribuição da metodologia de ACV na quantificação dos potenciais impactos ambientais no processo de produção de energia fotovoltaica e hidrelétrica. A metodologia consistiu de revisão sistemática em artigos, teses e dissertações em bancos de dados e portais de pesquisa científica. A sistematização foi estruturada em termos das categorias de impacto, métodos e softwares de quantificação e valores dos potenciais impactos das gerações hidrelétrica e fotovoltaica. Os resultados mostram que as maiores emissões de dióxido de carbono estão concentradas na fase de construção das hidrelétricas e dos módulos fotovoltaicos, sendo que a operação responde por uma parcela menor de emissões. A diferença entre os impactos de ambas as fontes geradoras se revela através das linhas de transmissão e distribuição, que são desconsideradas para geração distribuída. Como contribuição, o trabalho apresenta contribuições conceituais e dados numéricos para compreensão da problemática dos potenciais impactos ambientais oriundos de diversas matrizes energéticas.
\end{abstract}

Palavras-chave: Impactos Ambientais; Hidrelétrica; Fotovoltaica; Energia Elétrica.

\begin{abstract}
The use of photovoltaic panels for electric power generation is referred as a sustainable solution when compared to other forms of generation, such as nuclear and thermoelectric power plants. The Brazilian energy matrix is predominantly composed of hydroelectric plants, which despite the environmental impacts caused during the construction phase have a low emission of polluting gases and wastes during operation, and can also be considered a sustainable solution. The objective of this paper is to show how the studies of the environmental impacts of hydropower and photovoltaic sources are being approached and quantified and how the Life Cycle Assessment, LCA, has been used to quantify the potential impacts resulting from the implementation of these projects. For the present investigation, articles, theses and dissertations dealing with possible environmental impacts and their quantification were analyzed. The publications researched had their origin in national and international databases and portals. For the analysis, the impact categories cited by authors, the methods of impact quantification being used and which supporting software were searched. The results show that the largest emissions of carbon dioxide are concentrated in the construction phase of hydroelectric and photovoltaic modules, and the operation is responsible for a smaller portion of emissions. The key difference is on the impact caused by the transmission and distribution powerlines, absent in on-site generation. As contribution, this paper presents conceptual contributions and numerical data to understand the problematic of potential environmental impacts from several energy matrices.
\end{abstract}

Keywords: Environmental Impacts; Hydroeletric; Photovoltaic.

\section{INTRODUÇÃO}

Desde que a eletricidade se fez presente no contexto da humanidade se tornou artigo de necessidade, uma vez que todas as atividades da sociedade contemporânea requerem a sua 
utilização. A busca crescente por conforto e produtividade gera um acréscimo na demanda por eletricidade, e consequentemente, surge a necessidade da busca por novas fontes de energia.

Essas novas formas de geração de energia elétrica vêm ocupando um nicho na cadeia produtiva e a influenciados métodos de geração atuais no meio ambiente não pode ser analisada de forma pontual, fazendo-se necessário uma abordagem holística de seus potenciais nos alicerces econômico, social e ambiental da sustentabilidade(Siqueira, 2015).

$\mathrm{Na}$ realidade brasileira, grande parcela da produção de eletricidade advém de usinas hidrelétricas, e existe um amplo incentivo e regulamentação para adoção de micro geração por meio de painéis fotovoltaicos, rotulados comercialmente de "energia limpa" ou "renovável". $\mathrm{O}$ conceito de energia renovável está ligado às fontes que possuem a capacidade de se recuperar, nunca se esgotam, pois estão em constante renovação. As fontes renováveis são consideradas energias limpas devido à baixa agressão ao meio ambiente. Tanto a energia solar fotovoltaica como a energia hidrelétrica são aceitas como fontes de energia renovável (Santos et al., 2006).

Ao se caracterizar um processo de geração de energia em termos de sustentabilidade ambiental, foco do presente artigo, faz-se necessário considerar todos os serviços e produtos envolvidos e seus potenciais impactos no meio ambiente. Assim, para uma análise ambiental coerente desses dois processos de geração de energia, faz-se necessário considerar todas as emissões de carbono embutidas nos módulos fotovoltaicos desde a fase de extração dos minérios e manufatura e, analogamente, nas usinas hidrelétricas, as emissões acumuladas do processo de construção e transporte de materiais até o local da obra, bem como as emissões decorrentes do enchimento do reservatório. Nessa abordagem são consideradas as emissões acumuladas até a fase de uso, na qual a energia é disponibilizada para consumo.

A problemática englobando o critério de "energia renovável" das usinas hidrelétricas e dos módulos fotovoltaicos se encontra em seus distintos processos de conversão de energia e a tecnologia envolvida. Para o caso das usinas hidrelétricas, a energia potencial gravitacional é armazenada em barragens, convertida em energia cinética com o movimento da água e em energia elétrica pelos geradores (Tassinari, 2014). Essas conversões demandam estrutura física da usina que, por conseguinte, demanda minérios e derivados, concreto, mão-de-obra, transportes e maquinários, combustíveis, alterações no espaço físico, dentre outros. Paralelamente, para geração fotovoltaica, o minério semicondutor precisa ser extraído da natureza, processado, purificado, transportado e os componentes manufaturados.

Para ambos os casos, por mais distintos que sejam os processos, a cada etapa está associada um impacto ambiental específico. Uma maneira de desenvolver uma visão holística quanto aos impactos é acatar a energia elétrica como um produto, como diagnóstico dos impactos ambientais englobando toda a cadeia produtiva - extração de recursos, construção, operação e descomissionamento - criando assim uma visão macro da degradação ao meio ambiente decorrente de seu processo de produção.

A metodologia atualmente disponível para a quantificação global dos processos envolvidos na produção de um bem ou serviço é a Análise de Ciclo de Vida (ACV), entendida como uma técnica de avaliação e quantificação de impactos ligados à um processo ou produto, englobando os gastos energéticos associados àquela tarefa, desde o berço até $o$ túmulo, ou seja, desde aquisição e beneficiamento da matéria-prima até a destinação final, seja o descarte ou reciclagem (ABNT, 2009).

Com base no acima exposto, o objetivo desse artigo é demonstrar a contribuição da metodologia de ACV na quantificação dos potenciais impactos ambientais no processo de produção de energia fotovoltaica e hidrelétrica. Os objetivos específicos são: a) identificar as metodologias utilizadas para quantificação dos impactos e b) identificar a contribuição de cada etapa do ciclo da energia nos impactos ambientais totais. 
Como principal contribuição, o trabalho apresenta dados de emissões de gases de efeito estufa para hidrelétricas e módulos fotovoltaicos e alguns dados de energia incorporada para refletir sobre os impactos ambientais gerados por ambas as fontes e levantar a discussão sobre a forma atual de discutir a sustentabilidade ambiental de fontes geradoras de energia elétrica.

\section{MATERIAL E MÉTODOS}

A revisão sistemática é uma ferramenta de suporte com objetivo de reunir estudos similares para avaliar e sintetizar tópicos sobre determinado tema (Dreschet al., 2014). A primeira etapa para uma revisão sistemática é delimitar o objetivo do estudo, para se que realize uma busca criteriosa na literatura sobre os estudos relacionados à questão, para os quais será feita a sistematização das informações que subsidiam a resposta à problemática da pesquisa.

O tema de interesse da presente revisão sistemática trata dos impactos ambientais nas matrizes hidrelétrica e fotovoltaica. A questão na qual essa revisão se centraliza é: Como os impactos ambientais do processo produtivo de energia são abordados na literatura científica?

As bases de buscas utilizadas foram os portais: Science Direct; Scielo; Springer; The International Journal of Life Cycle Assessment e as bibliotecas digitais da Universidade Federal de Minas Gerais (UFMG), Pontifícia Universidade Católica de Minas Gerais (PUCMG), Universidade de São Paulo (USP), Universidade Federal do Rio de Janeiro (UFRJ), Universidade Federal Fluminense (UFF) e Universidade Federal de Lavras (UFLA).

As buscas envolveram os descritores "impacto ambiental", "hidrelétrica", "fotovoltaica" e "LCA" em combinações distintas, tanto na língua portuguesa quanto inglesa. A primeira busca com os descritores "impacto ambiental", "hidrelétrica" e "fotovoltaica" resultou em poucos estudos relevantes. Na busca seguinte fez-se uso da combinação de apenas dois descritores, sendo "impacto ambiental + hidrelétrica" e "impacto ambiental + fotovoltaica". Os resultados obtidos ainda possuíam relevância média ou baixa, o que demonstrou a necessidade de inclusão do termo "ACV" nas pesquisas e alteração do idioma para inglês. As pesquisas realizadas com os termos "LCA + hydroeletric" e "LCA + photovoltaic" resultaram em trabalhos de qualidade superior.

Neste processo de revisão sistemática, após a seleção inicial, foram aplicados os critérios para avaliação da qualidade, seguindo os pressupostos de Dreschet al. (2014), no qual são consideradas três dimensões para pré-avaliação. A primeira dimensão é a qualidade da execução, que mede como os estudos foram conduzidos e os dados foram analisados. A segunda e terceira dimensões avaliam os artigos quanto à questão e o foco da revisão. Desta forma, o material selecionado é classificado como de baixa, média ou alta nas três dimensões, subsidiando o processo de análise seguinte, a pós-avaliação, que envolve a consolidação baseada em uma média das dimensões anteriores.

A avaliação da qualidade, desta forma, serve como critério de inclusão dos trabalhos na pesquisa, sendo que, no caso dessa pesquisa, este critério fundamentou-se na obrigatoriedade de obtenção de alta qualidade nas três dimensões, considerados os critérios de ponderação da pós-avaliação da Tabela 1.

Quanto aos critérios de exclusão, buscou-se manter artigos e dissertações que citassem os impactos ambientais provenientes de construção de usinas hidrelétricas ou fabricação de módulos fotovoltaicos ou a comparação entre ambos. Por se tratar de um tema inovador, trabalhou-se com um critério temporal de 20 anos estabelecido como critério para delimitação dos estudos pesquisados. 
Ramos, L. A.; Durante, L. C.; Callejas, I. J. A. Geração de Eletricidade Abordando o Ciclo de Vida: Uma Revisão Sistemática sob a Ótica da Sustentabilidade Ambiental. E\&S - Engineering and Science, (2017), 6:1.

Tabela 1 - Critérios de Pós-avaliação

\begin{tabular}{c|c|c|c}
\hline \multicolumn{2}{c|}{ Avaliação do objeto selecionado quanto à } & Critério de ponderação \\
Qualidade da execução & $\begin{array}{c}\text { Adequação à questão da } \\
\text { revisão }\end{array}$ & $\begin{array}{c}\text { Adequação ao foco da } \\
\text { revisão }\end{array}$ & $\begin{array}{c}\text { Alta } \\
\text { Média }\end{array}$ \\
\cline { 1 - 2 } Alta & Alta & Alta & Média \\
Alta & Alta & Média & Média \\
Alta & Média & Média & Média \\
Alta & Média & Baixa & Baixa \\
Alta & Alta & Baixa \\
Média & Média & Baixa & Baixa \\
Média & Média & Baixa & Baixa \\
Baixa & Baixa & Baixa & Baixa \\
\hline
\end{tabular}

Fonte: Adaptado de Dreschet al. (2014)

\section{RESULTADOS E DISCUSSÕES}

Foram pré-selecionados 22trabalhos e após a aplicação dos critérios de pós-avaliação (Tabela 2), oito trabalhos. De todos os autores, somente oito comentam sobre ACV em seus textos (Tahara, 1997; Góralczyk, 2003; Ribeiro, 2003; Ribeiro e Silva, 2010; Pascale et al., 2011; Lima, 2012; Miranda, 2012; Turconi et al., 2013).

Tabela 2-Estudos pré-selecionados e critérios de pós-avaliação da qualidade

\begin{tabular}{|c|c|c|c|c|c|c|c|}
\hline \multirow[b]{2}{*}{ Referência } & \multirow[b]{2}{*}{ Ano } & \multirow[b]{2}{*}{ Tipo } & \multirow[b]{2}{*}{ Idioma } & \multicolumn{3}{|c|}{ Pré-avaliação } & \multirow{2}{*}{$\begin{array}{l}\text { Pós- } \\
\text { avalia- } \\
\text { ção }\end{array}$} \\
\hline & & & & $\begin{array}{c}\text { Qualidade } \\
\text { da execução }\end{array}$ & $\begin{array}{c}\text { Adequação à } \\
\text { questão da } \\
\text { revisão }\end{array}$ & $\begin{array}{c}\text { Adequação } \\
\text { ao foco da } \\
\text { revisão }\end{array}$ & \\
\hline Tahara, K. & 1997 & Artigo & Inglês & Alta & Alta & Alta & Alta \\
\hline Góralczyk & 2003 & Artigo & Inglês & Alta & Alta & Alta & Alta \\
\hline Ribeiro & 2003 & Dissertação & Português & Alta & Alta & Alta & Alta \\
\hline Shayniet al. & 2006 & Artigo & Português & Alta & Média & Média & Média \\
\hline Silva & 2007 & TCC & Português & Média & Média & Média & Média \\
\hline Gomes & 2010 & TCC & Português & Alta & Alta & Média & Média \\
\hline Ribeiro e Silva & 2010 & Artigo & Inglês & Alta & Alta & Média & Média \\
\hline Pascaleet al. & 2011 & Artigo & Inglês & Alta & Alta & Média & Média \\
\hline Nogueira & 2011 & Dissertação & Português & Alta & Média & Média & Média \\
\hline Lima & 2012 & Dissertação & Português & Alta & Alta & Alta & Alta \\
\hline Inatomi e Udaeda & 2012 & Artigo & Português & Alta & Alta & Alta & Alta \\
\hline Perius e Carregaro & 2012 & Artigo & Português & Alta & Média & Média & Média \\
\hline Miranda & 2012 & Dissertação & Português & Alta & Alta & Alta & Alta \\
\hline Turconiet al. & 2013 & Artigo & Inglês & Alta & Alta & Alta & Alta \\
\hline Silva & 2014 & Artigo & Português & Alta & Média & Alta & Média \\
\hline Brehm & 2014 & Dissertação & Português & Alta & Alta & Alta & Alta \\
\hline Scannapiecoet al. & 2014 & Artigo & Inglês & Alta & Alta & Média & Média \\
\hline Vahl & 2014 & Tese & Português & Alta & Alta & Média & Média \\
\hline Garcez & 2015 & Tese & Português & Alta & Média & Média & Média \\
\hline Dias & 2015 & Tese & Português & Alta & Média & Média & Média \\
\hline Suzigan & 2015 & Dissertação & Português & Alta & Baixa & Baixa & Baixa \\
\hline
\end{tabular}


Ramos, L. A.; Durante, L. C.; Callejas, I. J. A. Geração de Eletricidade Abordando o Ciclo de Vida: Uma Revisão Sistemática sob a Ótica da Sustentabilidade Ambiental. E\&S - Engineering and Science, (2017), 6:1.

\begin{tabular}{l|c|c|c|c|c|c|c}
\hline Ruela & 2016 & Tese & Português & Alta & Baixa & Baixa & Baixa \\
\hline \multicolumn{6}{l}{ Fonte: Autoria Própria }
\end{tabular}

Quatro trabalhos se utilizam do conceito de "payback energético" que reflete o tempo que um sistema de geração precisa operar para recuperar a energia utilizada para produzir o próprio equipamento que gera esta energia (Tahara, 1997; Ribeiro, 2003; Ribeiro e Silva, 2010; Brehm, 2014), sendo que Tahara (1997) trata de payback em termos de dióxido de carbono.

Seis autores fizeram análise simplificada por meio das emissões de carbono $\left(\mathrm{CO}_{2}\right)$ equivalente (Tahara, 1997; Goralczyk, 2003; Ribeiro, 2003; Ribeiro e Silva, 2010; Lima, 2012; Turconi et al., 2013) e quatro autores (Shayni et al, 2006; Pascale et al, 2011; Miranda, 2012; Garcez, 2015) citam a existência de emissões de $\mathrm{CO}_{2}$ sem quantificá-las.

Encaminham-se, a seguir, as contribuições conceituais e técnicas para promover a compreensão e a reflexão sobre o problema dos impactos ambientais da geração hidrelétrica e fotovoltaica, a partir da análise dos temas de interesse nos oito estudos selecionados para a sistematização.

Tahara et al. (1997) teve por objetivo estimar o potencial de redução das emissões de $\mathrm{CO}_{2}$ pela adoção de fontes renováveis de geração de energia elétrica, no Japão. Segundo dados da Agência Japonesa de Recursos Naturais e Energia, os autores afirmaram que, na data do estudo, $30 \%$ de todas as emissões de $\mathrm{CO}_{2}$ provinham do uso dos equipamentos elétricos utilizados na geração de energia da matriz, baseada em termelétricas, sendo a eficiência energética e a substituição por fontes renováveis contramedidas para o problema da emissão de $\mathrm{CO}_{2}$.

Para estimativa do potencial de redução das emissões de $\mathrm{CO}_{2}$, compararam as emissões de fontes renováveis com as emissões de fontes baseadas em combustíveis fósseis, utilizando a metodologia de Análise de Ciclo de Vida para usinas hidrelétricas, usinas solares fotovoltaicas, usinas baseadas em conversão de energia térmica oceânica e usinas termelétricas baseadas em carvão, óleo e gás natural. Para a definição das usinas, adotaram a solar fotovoltaica e a conversão de energia térmica oceânica como fontes alternativas; as usinas termelétricas à carvão, óleo e gás natural e as usinas hidrelétricas foram classificadas como fontes comerciais de energia.

As emissões de poluentes resultantes da construção das usinas e da produção dos materiais construtivos foram calculadas para cada unidade de geração de energia, sendo as quantificações dos materiais tomados de estudos anteriores. Referente às informações do Inventário de Ciclo de Vida, foram utilizados dados secundários compilados anteriormente e os dados faltantes foram obtidos junto às companhias relacionadas, como a mineradoras, fabricantes e afins.

Além das emissões de $\mathrm{CO}_{2}$ derivadas da queima de combustíveis fósseis, também foram consideradas as emissões provenientes da produção dos combustíveis, da eletricidade e dos materiais. Para os materiais importados, a fronteira foi definida no portão dos países importadores, o que significa que as emissões de $\mathrm{CO}_{2}$ em tais países foi desconsiderada e as emissões do transporte de produtos estão incluídas nos cálculos. Os dados de extração de matéria-prima, incluindo combustíveis fósseis, também foram excluídos, sendo que o Japão importa $100 \%$ de seu alumínio e $65 \%$ da nafta.

Utilizaram para o cálculo, o software NIRE-LCA, desenvolvido pelo Instituto Nacional de Recursos e Meio Ambiente do Japão. Seus resultados apontam payback de $\mathrm{CO}_{2}$ para as fontes de geração citadas.

Em seus resultados, as emissões de $\mathrm{CO}_{2}$ durante a construção das usinas foram divididas pela geração anual de eletricidade devido à diferença entre a capacidade de geração de cada usina (Quadro 1). As maiores emissões durante a construção são das três usinas solares fotovoltaicas analisadas, flutuando entre 3,41 e 4,3 $\mathrm{kgCO}_{2} /(\mathrm{kWh} / \mathrm{ano})$. Para as usinas 
baseadas em conversão de energia térmica oceânica, os valores variam com a potência instalada, sendo 2,23 e $0,25 \mathrm{kgCO}_{2} /(\mathrm{kWh} / \mathrm{ano})$ para as usinas de 2,5 e $100 \mathrm{MW}$, respectivamente. Na hidrelétrica, a emissão encontra-se em $0,39 \mathrm{kgCO}_{2} /(\mathrm{kWh} / \mathrm{ano})$. As termelétricas possuem valores de $0,016 \mathrm{kgCO}_{2} /(\mathrm{kWh} / \mathrm{ano})$ para ambas as usinas baseadas em óleo e gás natural, e a emissão para a usina baseada em carvão assume valores de 0,022 $\mathrm{kgCO}_{2} /(\mathrm{kWh} / \mathrm{ano})$.

Quadro 1 - Emissões de $\mathrm{CO}_{2}$ das fontes geradoras durante construção e por kWh gerado

\begin{tabular}{c|c|c}
\hline \multirow{2}{*}{ Geração } & \multicolumn{2}{|c}{ Emissões $\left[\mathrm{kgCO}_{2} /(\mathrm{kWh} / \mathrm{ano})\right]$} \\
\cline { 2 - 3 } & $\begin{array}{c}\text { Fase de } \\
\text { construção }\end{array}$ & Fase da operação \\
\hline Carvão & 0,0221 & 0,9159 \\
\hline Óleo & 0,0164 & 0,7557 \\
\hline Gás Natural & 0,0160 & 0,5630 \\
\hline Hidrelétrica & 0,3954 & 0,0171 \\
\hline OTEC (2,5 MW) & 2,2305 & 0,1190 \\
\hline OTEC (100 MV) & 0,2554 & 0,1360 \\
\hline Fotovoltaica 1 & 3,5400 & 0,1534 \\
\hline Fotovoltaica 2 & 3,4143 & 0,1480 \\
\hline Fotovoltaica 3 & 4,3070 & 0,1866 \\
\hline
\end{tabular}

Fonte: Adaptado de Tahara et al. (1997)

Quando os autores expõem os valores das emissões de $\mathrm{CO}_{2}$ por $\mathrm{kWh}$ gerado, os maiores valores são das usinas termelétricas: $0,91 \mathrm{kgCO}_{2} / \mathrm{kWh}$ para queima de carvão; 0,75 $\mathrm{kgCO}_{2} / \mathrm{kWh}$ para queima de óleo e 0,56 para o gás natural. Na sequência, estão as usinas solares fotovoltaicas, com emissões de 0,$18 ; 0,15$ e $0,14 \mathrm{kgCO}_{2} / \mathrm{kWh}$. Para as usinas baseadas em conversão de energia térmica oceânica as emissões são de $0,11 \mathrm{kgCO}_{2} / \mathrm{kWh}$ e 0,01 $\mathrm{kgCO}_{2} / \mathrm{kWh}$ para as usinas de 2,5 MW e $100 \mathrm{MW}$, respectivamente. A hidrelétrica possui o menor valor de emissões dentre todas, de $0,017 \mathrm{kgCO}_{2} / \mathrm{kWh}$.

Para o tempo de retorno de $\mathrm{CO}_{2}$, os menores tempos são encontrados quando a matriz energética é baseada em termelétricas à carvão, sendo que a adoção de hidrelétricas nessas condições possui tempo de retorno de 4 meses e 28 dias. Enquanto para mesma condição, o tempo de retorno das usinas solares fotovoltaica varia entre 3,85 anos e 4,91 anos.

Os resultados encontrados por Tahara et. al. (1997) para as emissões de $\mathrm{CO}_{2}$ durante a construção de usinas de geração de energia elétrica assumem valores discrepantes, possivelmente pela escolha das fronteiras na $\mathrm{ACV}$ e do indicador $\mathrm{kgCO}_{2} /(\mathrm{kWh} / \mathrm{ano})$, que faz com que a capacidade de geração da usina altere os valores de emissão significativamente. Tal fato pode ser visto claramente nas duas usinas de conversão de energia térmica oceânica, que possuem capacidade instalada com uma diferença de 40 vezes entre uma e outra, o que acaba por gerar uma diferença com multiplicador 10 em seus indicadores de emissão de $\mathrm{CO}_{2}$, tanto para construção quanto para operação. Um fator a ser observado nas termelétricas a óleo e gás natural é a diferença na eficiência de ambas, que possuem os mesmos valores de emissão durante a construção, mas durante a operação, a termelétrica a gás natural possui valores de emissão sutilmente inferiores à termelétrica à óleo. Outro valor que chama atenção em seus resultados são as emissões das usinas solares fotovoltaicas comparadas à hidrelétrica, que chegam a ser 10 vezes maiores, tanto para construção quanto para operação.

Goralczyk (2003) analisa os impactos ambientais da produção de 1 GJ de energia elétrica por meio de painéis fotovoltaicos, turbinas eólicas e hidrelétrica, considerando as fases de construção, operação e eliminação de resíduos das usinas. 
Aplica a metodologia da ACV, com identificação de todas as entradas e saídas em Inventário de Ciclo de Vida fornecidos pelas concessionárias de energia e fabricantes de componentes, não fazendo referência ao software utilizado como ferramenta para o desenvolvimento. Para traduzir os resultados do inventário para a Análise de Impacto do Ciclo de Vida (AICV), as seguintes categorias de impacto foram adotadas: depleção de recursos, efeito estufa, acidificação e eutrofização. Para quantificação das categorias de impacto, as emissões de $\mathrm{CO}_{2}$ estão relacionadas ao efeito estufa, enquanto as emissões de fréons afetam tanto o efeito estufa quanto a depleção de ozônio. As emissões de $\mathrm{SO}_{2} \mathrm{e} \mathrm{NO}_{\mathrm{x}}$ qualificam a acidificação, contribuindo para as chuvas ácidas e impactando nas florestas e no ecossistema aquático. Os dados do inventário utilizados são oriundos de bases australianas, europeias e britânicas.

A principal conclusão do autor transparece que a energia gerada por uma fonte hidrelétrica tem alta eficiência e as emissões de $\mathrm{CO}_{2}\left(1,27 \mathrm{kgCO}_{2}\right)$ são $40 \%$ menores que as termelétricas à carvão. Dentre as fontes renováveis, a solar fotovoltaica apresenta os maiores valores de emissão de gases causadores de efeito estufa $\left(29 \mathrm{kgCO}_{2}\right)$ e resíduos $(6,4 \mathrm{~g})$.

$\mathrm{O}$ autor também destaca como a ferramenta de ACV pode ser usada para manejar economicamente e ecologicamente os recursos naturais, tornando seu consumo mais eficiente e mantendo um nível satisfatório das reservas. A ACV possibilita a visualização dos impactos produzidos pelas fontes em cada categoria individualmente, fomentando as decisões para preservação do meio de acordo com as necessidades locais. Por exemplo, em uma região com problemas de eutrofização seria mais sensato adotar uma fonte de geração de energia que elimina uma quantidade menor de resíduos na água, não contribuindo para o florescimento de algas.

Ribeiro (2003)foi pioneiro nos estudos de Análise de Ciclo de Vida no Brasil, criando uma proposta de Inventário de Ciclo de Vida para a Usina de Itaipu. A escolha de Itaipu se deve ao fato da sua elevada contribuição na produção de energia, que correspondia a $22,4 \%$ da eletricidade consumida no país, no ano 2000. O tempo de vida de 100 anos foi tomado como referência, considerando a obra civil da usina e a totalidade de seus insumos, resultando em um ICV com os aspectos ambientais refletidos em termos de energia gerada (MWh).

Focando na ferramenta de Análise de Ciclo de Vida para avaliação ambiental, o autor é um dos poucos que inclui em sua discussão o descomissionamento das usinas como impacto ambiental a ser considerado. Sua abordagem permite a quantificação das emissões de $\mathrm{CO}_{2} \mathrm{em}$ cada processo da geração de eletricidade, incluindo a energia acumulada durante a construção da usina. Para modelagem dos processos utilizou-se do software SimaPro, adotando a unidade funcional de $1 \mathrm{MWh}$ gerado.

Para o primeiro momento da coleta de dados, o autor quantificou o aço, cimento e diesel utilizados na construção e operação da usina. No segundo momento, os aspectos ambientais referentes à obtenção dos insumos anteriormente citados foram estimados. Para definir as fronteiras de influência da usina, considerou a esfera ambiental, os bens de capital e uma associação de conhecimento de terceiros. Quanto à esfera ambiental, a usina interage com a água captada do rio e incorpora bens como a terra, rocha e areia retiradas das proximidades e usadas na construção. Quanto às fronteiras de bens de capital, foram consideradas as obras de infraestrutura habitacional e o canteiro de obras. Com relação às demais fronteiras adotadas, o autor optou por utilizar o conhecimento prévio de terceiros no assunto, chegando aos principais insumos da construção como sendo aço, cobre, diesel, óleo lubrificante, óleo de transformador e cimento.

Uma das conclusões do autor refere-se ao fato de que cada hidrelétrica constitui-se em um caso particular, impossibilitando a adoção de valores típicos de impactos e, que Itaipu possui um desempenho ambiental acima da média devido a seu fator de capacidade e potência instalada. Suas estimativas mostram que os processos que mais contribuem aos aspectos 
ambientais são o enchimento do reservatório, ciclo de vida do aço e cimento e operação de máquinas de construção.

Em termos de emissão de $\mathrm{CO}_{2}$, os dados apontam para uma estimativa de $1,39.10^{10} \mathrm{~kg}$ de $\mathrm{CO}_{2}$ durante todo o ciclo de vida de Itaipu, sendo 28,5\% desse valor emitidos durante a construção e 71,5\% emitidos durante os 100 anos de operação. Ao categorizar as emissões por processo, o autor mostra que $69,2 \%$ estão concentradas na formação do reservatório. Em contrapartida, $16,7 \%$ das emissões totais são derivadas do ciclo de vida do cimento. As emissões restantes estão divididas entre a operação das máquinas de construção $(8,1 \%)$, ciclo de vida do aço $(4,2 \%)$, ciclo de vida do cobre $(1,1 \%)$, transporte do cimento $(0,4 \%)$, transporte de ônibus $(0,1 \%)$, transporte de aço estrutural $(0,1 \%)$ e outros $(0,1 \%)$.

Referente às emissões de metano, a predominância, assim como as emissões de $\mathrm{CO}_{2}$, se encontram na formação do reservatório, respondendo por $99,5 \%$ de um total de $1,18.10^{9} \mathrm{~kg}$ de metano emitidos. As emissões restantes são provenientes do ciclo de vida do aço.

A emissão de monóxido de carbono totaliza $9,98.10^{8} \mathrm{~kg}$, sendo $63,6 \%$ na construção da usina e 36,4\% durante os 100 anos de operação. A maior contribuição é do ciclo de vida do aço, respondendo por $99,4 \%$ das emissões totais de monóxido de carbono.

A emissão de material particulado foi estimada em $2,22.10^{8} \mathrm{~kg}$, sendo $78,6 \%$ na construção e $21,4 \%$ na operação. O ciclo de vida do aço responde por $58,3 \%$ do material particulado emitido. Referente às emissões de óxidos de enxofre, a estimativa é de $3,35.10^{7}$ $\mathrm{kg}$, com a maior representação durante a construção $(55,9 \%)$, sendo o ciclo de vida do cobre e do aço responsáveis por $40,4 \%$ e $40,2 \%$ do total de emissões, respectivamente.

Durante todo o ciclo de vida de Itaipu, as emissões de óxido de nitrogênio foram estimadas em $2,66.10^{7} \mathrm{~kg}$, com a operação das máquinas de construção respondendo por $59,9 \%$ da emissão total.

Em relação ao payback energético, o autor quantifica toda a energia envolvida em todos os processos do ciclo de vida da usina de Itaipu, chegando ao valor de 7,93.10 ${ }^{10} \mathrm{MJ}\left(2,2.10^{7}\right.$ MWh) de energia consumidos para construção e operação da usina por 100 anos. Ao considerar a potência instalada na usina e seu fator de capacidade, Itaipu geraria toda a energia consumida ao longo de seu ciclo de vida em 93 dias. Esse resultado é um valor reduzido para um tempo de vida longo.

Para fins de comparação, o autor buscou dados de ciclo de vida de usinas termelétricas a gás natural. Dados europeus da base de dados do software SimaPro foram utilizados pela inexistência de dados brasileiros e como esses dados não representam a realidade, o autor buscou dados regionais de emissões por MWh em estudos e relatórios de impactos ambientais (EIA/RIMA) de quatro usinas. As emissões de $\mathrm{NO}_{\mathrm{x}}, \mathrm{SO}_{\mathrm{x}}$, material particulado, $\mathrm{CO}, \mathrm{CO}_{2} \mathrm{e}$ $\mathrm{CH}_{4}$ apresentaram valores bem reduzidos em Itaipu quando confrontados com as quatro termelétricas.

Lima (2012) tem por objetivo propor uma metodologia para o projeto de sistemas de geração de energia elétrica para Edifícios de Energia Zero, com a fonte geradora de energia perto do consumidor, reduzindo a necessidade de linhas de transmissão e distribuição.

$\mathrm{O}$ autor comenta de forma qualitativa sobre os impactos socioambientais das hidrelétricas, caracterizados pelas áreas alagadas dos reservatórios, impactos na fauna e flora e necessidade do deslocamento de comunidades para implantação das usinas. Destaca que uma das formas de reduzir o impacto ambiental é reduzindo o desperdício de energia elétrica na rede de transmissão por meio da geração distribuída, que aproxima a fonte geradora do ponto de consumo, acarretando diminuição nas perdas na distribuição e transmissão de eletricidade.

O principal argumento sobre a adoção de fontes de geração distribuída está relacionado às perdas nas linhas de transmissão e distribuição. O autor cita que em 2010, tal perda foi de 
$17,2 \%$ no Sistema Interligado Nacional, equivalentes a 88,2 TWh, suficientes para abastecer 47,7 milhões de residências médias (EPE, 2011).

Dessa contextualização, surgiram os Edifícios de Energia Zero (EEZ), que são edificações com baixas necessidades energéticas e geram toda a energia que consomem. A grande vantagem da adoção desse modelo é adiar ou evitar a construção de novas hidrelétricas no Brasil. Propõe como solução para minimização dos impactos a adoção de Edifícios de Energia Zero no Ciclo de Vida (EEZ-CV), que devem considerar a energia incorporada nos materiais de construção para fins de compensação durante sua vida útil.

O autor discorre como a equação proposta por Hernandez e Kenny (2010) pode ser utilizada para tomar decisões baseadas no conceito de relação de energia líquida, que relaciona a energia incorporada durante a produção com a energia gasta para operação. Cita a necessidade do uso de Inventários de Ciclo de Vida (ICV) para quantificação energética dos edifícios e a dificuldade pela falta de acesso e dados de inventário para os materiais construtivos.

Quanto aos módulos fotovoltaicos, não cita diretamente seus impactos, mas expõe dados secundários de Energia Incorporada $\left(\mathrm{MJ} / \mathrm{m}^{2}\right)$ para as diferentes tecnologias de painéis, onde a maior quantidade se encontra nos módulos de silício monocristalino $\left(4200 \mathrm{MJ} / \mathrm{m}^{2}\right)$, seguido pelos de silício policristalino $\left(3700 \mathrm{MJ} / \mathrm{m}^{2}\right)$, amorfo $\left(1202 \mathrm{MJ} / \mathrm{m}^{2}\right)$, telureto de cádmio $\left(1200 \mathrm{MJ} / \mathrm{m}^{2}\right)$, disseleneto de gálio e índio $\left(1069 \mathrm{MJ} / \mathrm{m}^{2}\right)$ e módulos de multijunção silício amorfo/monocristalino $\left(587 \mathrm{MJ} / \mathrm{m}^{2}\right)$.

Para modelagem da geração e consumo de energia foram aplicadas as ferramentas Energy Plus, Homer Energy e RETScreen. Adotou como objeto de estudo um edifício de laboratórios em Campinas-SP. Levantou, primeiramente o consumo de energia do edifíciopor meio de simulação no EnergyPlus, para após isso dimensionar a geração através dos dados disponibilizados pelo CRESESB e simular a geração através do RTScreen e Homer Energy.

A próxima etapa envolveu o cálculo do tempo de retorno da energia, contabilizado através da energia incorporada utilizando a Análise de Ciclo de Vida. O autor usou dados secundários para quantificação dos produtos e serviços e desconsiderou a energia incorporada no transporte dos equipamentos dos locais de fabricação até o local de instalação. Para o balanço do sistema fotovoltaico incluindo inversor, instalação, fiação e demais componentes o valor considerado pelo autor foi quantificado em 4279 MJ por Kwp (Lima, 2012 apud Bravi e Parisiet al., 2011).Com propostas de sistemas fotovoltaicos de três empresas distintas, os resultados de tempo de retorno energético são de 3,6; 4,7 e 5 anos. Tal variação se deve pela escolha da tecnologia adotada.

Inatomi e Udaeta (2012) discorrem sobre a mitigação dos impactos ambientais das fontes de geração de energia elétrica através de um Planejamento Integrado de Recursos aplicado ao planejamento energético, que consiste de uma ferramenta para mitigar os impactos ambientais provocados pela busca do desenvolvimento econômico. É um método de planejamento em curto e longo prazo que considera a dimensão social, técnica, econômica e a ambiental. Inclui análise sobre as características da região, disponibilidade de recursos, dados de oferta e demanda e análise de custo.

Os autores ponderam que as hidrelétricas não podem ser consideradas uma ótima solução ecológica devido à interferência no fluxo dos rios, destruição de espécies vegetais e da fauna e alteração na ocupação humana. Destacam que a implantação de hidrelétricas pode gerar impactos ambientais na hidrologia, clima, erosão e assoreamento, sismologia, fauna, flora e alteração de paisagens.

Para quantificação dos impactos, comentam sobre a abordagem adotada pelo Centro de Pesquisas de Energia Elétrica (CEPEL), rotulados em seis categorias de análise ecossistemas aquáticos, ecossistemas terrestres, modo de vida, organização territorial, base econômica e população indígena. Para melhor quantificação e caracterização dos impactos 
ambientais provenientes da implantação de hidrelétricas sugerem a avaliação através de indicadores de impacto, como hierarquia fluvial, perda de lagoas marginais, comprometimento de rotas migratórias, espécies exclusivas, alteração da vegetação, qualidade da água, perda de vegetação marginal, taxa de cobertura vegetal, relevância da fauna, exclusividade fisionômica, hectares inundados $/ \mathrm{kWh}$ gerado, toneladas emitidas de metano/volume de água, dólares de dano ao Meio Ambiente/alagamento de terra, entre outros.

Quanto aos sistemas fotovoltaicos, discorrem sobre os impactos associados à produção de energia necessária no processo de fabricação dos componentes, transporte, instalação, operação, manutenção e descomissionamento, emissões de produtos tóxicos durante o processo da matéria-prima, ocupação de área para implementação do projeto, impactos visuais e riscos associados ao descarte de materiais tóxicos. Indicadores de impacto também são citados, bem como gases poluentes não emitidos na atmosfera, riscos de acidentes em manutenção por $\mathrm{kWh}$, riscos de incêndio por produção de energia, ciclo de vida dos componentes do sistema, emissão de poluentes no processo de fabricação dos componentes, emissão de poluentes por riscos de acidentes, entre outros.

Todas as formas de obtenção de energia possuem seus aspectos positivos e negativos. Com o Planejamento Integrado de Recursos é possível analisar a real necessidade de implantação de um projeto energético, mitigar os impactos ambientais e promover o desenvolvimento sustentável. O Planejamento Integrado de Recursos se assemelha à Avaliação de Ciclo de Vida, diferindo nas categorias de impacto ambiental e na abordagem holística deste, que se inicia na extração dos recursos naturais, visão ausente no PIR.

Miranda (2012) trata da Avaliação do Ciclo de Vida (ACV) para o cálculo do fator de emissão de gases de efeito estufa da matriz de energia elétrica brasileira. Através de uma revisão sistemática com meta-análise identifica os estudos que estimam as emissões de gases de efeito estufa, demonstrando que a energia eólica e a nuclear apresentam menores emissões, enquanto as emissões provenientes de hidrelétricas sofrem grande variação pela dependência das características dos reservatórios. Cita que, para as fontes renováveis, $90 \%$ as emissões de gases de efeito estufam encontram-se na fase anterior e posterior à geração de eletricidade, descrito com uma verossimilhança mais abrangente pela ACV. Separa os impactos ambientais em upstream - que ocorrem antes da geração de energia, na etapa de exploração de materiais, construção da usina e transporte - impactos diretos, relacionados a operação e manutenção da usina, e impactos downstream - que ocorrem após a geração, como na gestação de resíduos e desativação da usina.

Cita a publicação do Segundo Inventário de Ciclo de Vida Brasileiro, no ano de 2010, que contém estimativas de emissões de $\mathrm{CO}_{2}, \mathrm{CH}_{4}, \mathrm{~N}_{2} \mathrm{O}, \mathrm{HFCs}, \mathrm{PFCs}, \mathrm{SF}_{6}$ e de gases de efeito estufa indiretos. Tal Inventário adapta a metodologia definida pelo Painel Intergovernamental sobre Mudanças Climáticas (IPCC) para o contexto brasileiro, excluindo as emissões de metano para as hidrelétricas por falta de definição de metodologia adequada. Apresenta fatores de emissão nos reservatórios em $\mathrm{gCO}_{2} \mathrm{eq} / \mathrm{kWh}$ para 12 usinas brasileiras, considerando sua construção e enchimento do reservatório, incluindo a Usina Hidrelétrica Manso (677,93 $\mathrm{gCO}_{2} \mathrm{eq} / \mathrm{kWh}$ ).

Turconi et al. (2013) faz uma revisão em 167 estudos de caso envolvendo a Análise de Ciclo de Vida da geração de energia elétrica através de carvão, gás natural, óleo, nuclear, biomassa, hidrelétrica, fotovoltaica e eólica para identificar a faixa das emissões de gases causadores de efeito estufa, $\mathrm{NO}_{\mathrm{x}}$ e $\mathrm{SO}_{2}$. O autor cita que a $\mathrm{ACV}$, a pegada de carbono e outras contabilizações de Gases de Efeito Estufa (GEE) são comumente usadas como ferramentas de suporte para tomadas de decisão.

A ACV associa os potenciais impactos com o ciclo de vida do produto ou serviço por meio da elaboração de um Inventário de Ciclo de Vida, que relaciona as entradas, saídas e emissões relevantes associadas ao produto ou serviço em questão. Embora a pegada de 
carbono atraia mais atenção que $\mathrm{ACV}$, por ser constituída de apenas um indicador pode refletir uma simplificação exacerbada do sistema. A visão holística da $\mathrm{ACV}$, mesmo que reflita apenas os gases causadores de efeito estufa, é comumente mais aceita na comunidade científica.

Dos estudos selecionados pelo autor, 12 referem às usinas hidrelétricas e 22 às usinas fotovoltaicas, que correspondiam a $16 \%$ e $0,1 \%$ da geração mundial de eletricidade em 2008 , respectivamente.

Quanto aos registros dos estudos de caso, a faixa de emissão de dióxido de carbono varia entre 2-20 $\mathrm{kgCO}_{2} \mathrm{eq} / \mathrm{MWh}$ para as hidrelétricas e entre $13-190 \mathrm{kgCO}_{2} \mathrm{eq} / \mathrm{MWh}$ para a produção solar fotovoltaica. As emissões de óxido de nitrogênio assumem valores, para hidrelétrica, na faixa de $0,004-0,06 \mathrm{kgNO}_{\mathrm{x}} / \mathrm{MWh}$ e para fotovoltaica, $0,15-0,40 \mathrm{kgNO}_{\mathrm{x}} / \mathrm{MWh}$. Os valores encontrados de óxidos de enxofre também são menores nas hidrelétricas $(0,001$ $\left.0,03 \mathrm{kgSO}_{2} / \mathrm{MWh}\right)$ do que na fotovoltaica $\left(0,12-0,29 \mathrm{kgSO}_{2} / \mathrm{MWh}\right)$, sendo todos relacionados ao tempo de vida total de cada caso estudado.

Referente às variações nas emissões equivalentes nas hidrelétricas, fatores identificados de grande influência são o tamanho do reservatório, profundidade, tipo e quantidade de matéria orgânica submersa, tipo de solo, clima da região da usina, que alteram as emissões de metano pela decomposição anaeróbica de matéria orgânica submersa no reservatório consideravelmente. Enquanto as emissões de $\mathrm{CO}_{2}$ variam entre 0,35-30 $\mathrm{kgCO}_{2} \mathrm{eq} / \mathrm{MWh}$ para regiões da Finlândia, as emissões no Brasil podem atingir o pico de $340 \mathrm{kgCO}_{2} \mathrm{eq} / \mathrm{MWh}$.

Sobre a variação encontrada nos painéis fotovoltaicos, o autor discorre sobre a dependência da matriz energética principal do local de fabricação dos módulos. Com o mesmo método produtivo, as matrizes mais sustentáveis são capazes de produzir painéis com menores valores de emissões. Como exemplo, o autor cita um estudo de fabricação de um módulo fotovoltaico no Brasil e na Alemanha. Para o caso alemão, o fator de emissão de tal módulo seria $530 \mathrm{kgCO}_{2} \mathrm{eq} / \mathrm{MWh}$, enquanto para o Brasil, a emissão seria de 70 $\mathrm{kgCO}_{2} \mathrm{eq} / \mathrm{MWh}$.

Brehm (2014) tem por objetivo em seu estudo analisar o panorama da microgeração fotovoltaica distribuída em pequenos consumidores para inferir se tal tecnologia seria viável como fonte geradora de energia exossomática. Trata de aspectos socioambientais da geração fotovoltaica distribuída e cita o estudo intitulado "Análise de ciclo de vida integrado para cenários de geração de eletricidade", destacando a diminuição do potencial poluidor das células fotovoltaicas quando comparadas com os métodos de geração de energia baseados em combustão.

Utiliza do conceito de "payback energético" que reflete o tempo que um sistema de geração fotovoltaica precisa operar para recuperar a energia utilizada para produzir o próprio equipamento que gera esta energia, citando que um painel fotovoltaico operando no sul da Europa tem um tempo de payback energético em torno de um ano. Adotou em sua metodologia o software PVWatts, para estimar os valores de energia gerados em relação a diferentes localidades e criar cenários de geração distribuída para argumentar a favor da viabilidade ambiental dos painéis fotovoltaicos.

Pela análise das publicações, nas de âmbito brasileiro, existe predominância de temas que abordam os impactos ambientais gerados pelas hidrelétricas. Shayni et. al. (2006), Nogueira (2011), Brehm (2014) e Vahl (2014) abordam a problemática dos impactos gerados pelo sistema de transmissão e distribuição, que podem ser mitigados com a adoção de fontes de geração próximas aos pontos de consumo, tal qual ocorre com os painéis fotovoltaicos residenciais. Por meio da análise destes trabalhos, observa-se uma tendência entre os autores que não abordam a Análise de Ciclo de Vida em tratar os impactos das hidrelétricas de forma pontual, com impacto ambiental associado à bacia de instalação da usina. Muitos citam os impactos advindos da área alagada e degradação da fauna e flora, porém poucos comentam as 
emissões de gás metano, extremamente crítica e mais impactante que gás carbônico para atmosfera, enquanto Silva (2007), Nogueira (2011), Lima (2012), Inatomi et al. (2012) e Dias (2015) e possuem a visão sobre os impactos ambientais causados pelo processo de fabricação de módulos fotovoltaicos.

Já os autores que trabalham com o conceito de Análise de Ciclo de Vida apresentam uma tendência de globalização dos impactos ambientais, saindo do foco pontual e considerando impactos como o potencial de aquecimento global, acidificação, eutrofização, depleção da camada de ozônio e de recursos e demanda energética, convertendo todos os valores de impacto para $\mathrm{gCO}_{2} \mathrm{eq} / \mathrm{kWh}$.

Referente às emissões de $\mathrm{CO}_{2}$ equivalente, que incluem a conversão de todos os gases de efeito estufa em $\mathrm{CO}_{2}$, o Quadro 2 apresenta um resumo dos valores apresentados pelos autores.

Quadro 2 - Consolidação das emissões de Gases de Efeito Estufa

\begin{tabular}{|c|c|c|}
\hline \multirow{2}{*}{ Referência } & \multicolumn{2}{|c|}{ Emissões $\left[\mathrm{kgCO}_{2}\right.$ eq/kWh $]$} \\
\cline { 2 - 3 } & Hidrelétrica & Fotovoltaica \\
\hline \multirow{2}{*}{ Tahara et al. (1997) } & \multirow{3}{*}{0,017} & 0,148 \\
\cline { 3 - 3 } & & 0,153 \\
\hline Goralczyk (2003) & 0,016 & 0,187 \\
\hline Ribeiro (2003) & 0,005 & 0,104 \\
\hline \multirow{2}{*}{ Lima (2012) } & \multirow{2}{*}{0,015} & - \\
\cline { 3 - 3 } & & 0,079 \\
\hline Turconi et al. (2013) & $0,002-0,02$ & 0,086 \\
\hline
\end{tabular}

Fonte: Autoria Própria

Os valores para as hidrelétricas se mostram, em geral, menores em relação à fotovoltaica. Uma das justificativas é o local de fabricação dos painéis, geralmente com matrizes energéticas de predominância termelétrica. Tal predominância afeta negativamente as emissões oriundas dos painéis fotovoltaicos. Tahara et al. (1997) e Goralczyk (2003) apresentam valores próximos de emissões para os painéis fotovoltaicos. Turconi et al. (2013) apresenta uma faixa de emissões, tanto para os painéis fotovoltaicos quanto para as hidrelétricas, não sendo possível a identificação da causa da discrepância em seus valores. Lima (2012) justifica a diferença entre as emissões nas hidrelétricas pela tipologia do reservatório adotado, onde os reservatórios com maiores áreas para usinas de baixa produção energética pioram o indicador de $\mathrm{kgCO}_{2} \mathrm{eq} / \mathrm{kWh}$.

\section{CONCLUSÕES}

A principal forma de diminuir os impactos ambientais causados pela geração de eletricidade é aproximar a fonte geradora da demanda, reduzindo a necessidade do uso de linhas de transmissão e distribuição, argumento corroborado por Lima (2012) e Brehm (2014).

A geração distribuída, favorecida pela regulamentação brasileira da microgeração em 2012, está em expansão. Esse crescimento se deve a adoção de políticas de incentivo à geração fotovoltaica, que não reflete necessariamente uma tendência ambientalmente sustentável quando confrontada com a geração hidrelétrica - que possuem dados discrepantes quanto as suas emissões de gases, variando em função do tamanho do reservatório e tipo de usina adotada. 
Quanto as categorias de impacto ambiental referentes às fontes hidrelétricas e fotovoltaicas, elas assumem características diferentes baseadas nas visões de cada autor. Quando o conceito de ACV está embutido nos textos, a visão dos impactos assume uma característica global, que reflete toda energia incorporada no sistema através das emissões de $\mathrm{CO}_{2}$. Na ausência do conceito de ACV, os autores discorrem individualmente sobre cada impacto ambiental de ambas as fontes, dificultando uma comparação entre as gerações.

Para apoiar a ACV, são necessários softwares auxiliares, como o SimaPro, e metodologias adequadas para cada caso, seja através do uso de indicadores ou análises estatísticas específicas.

Em relação à visão de sustentabilidade dos painéis fotovoltaicos, o marketing adotado segue um modelo internacional baseado em comparações com termelétricas. Realidade essa que difere da brasileira. $\mathrm{O}$ aspecto econômico pode e precisa ser considerado, mas o ambiental é tão importante quanto.

\section{REFERÊNCIAS}

ASSOCIAÇÃO BRASILEIRA DE NORMAS TÉCNICAS.NBR ISO 14040: Gestão Ambiental - Avaliação do Ciclo de Vida - Princípios e Estrutura. Rio de Janeiro, 2009. 10 p.

BREHM, M. A. Geração de Energia Elétrica Fotovoltaica Distribuída por Pequenos Consumidores Domésticos no Paraná: Potencialidades e Aspectos Sócio-Ambientais. 2014. 89 f. Dissertação (Mestrado) - Curso de Programa de Pós-graduação em Meio Ambiente e Desenvolvimento, Universidade Federal do Paraná, Curitiba, 2014.

DRESCH, A.; LACERDA, D. P; JÚNIOR, J. A. V. A. Design Science Research: Método de Pesquisa para Avanço da Ciência e Tecnologia. Porto Alegre: Bookman, 2014. 204p.

EMPRESA DE PESQUISA ENERGÉTICA. Ministério de Minas e Energia. Balanço Energético Nacional: Relatório Síntese (ano base 2015). Rio Janeiro, 2016. Disponível em: https://ben.epe.gov.br/downloads/Síntese do Relatório Final_2016_Web.pdf. Acesso em: 10 set. 2016.

GARCEZ, C. A. G. Políticas de Geração Distribuída de Sustentabilidade do Sistema Elétrico.2015. 201 f. Tese (Doutorado) - Curso de Centro de Desenvolvimento Sustentável, Universidade de Brasília, Brasília, 2015.

GOMES, C. G. S. Noções de Geração Utilizando Fontes de Baixo Impacto Ambiental.2010. 92 f. TCC (Graduação) - Curso de Engenharia Elétrica, Departamento de Engenharia Elétrica, Universidade Federal do Rio de Janeiro, Rio de Janeiro, 2010.

GORALCZYK, M. Life-cycle Assessment in the Renewable Energy Sector. Applied Energy, Krakow, v. 75, p.205-211, dez. 2002.

INATOMI, T. A. H; UDAETA, M. E. M. Análise dos Impactos Ambientais na Produção de Energia.2012. Disponível em: <http://seeds.usp.br/portal/uploads/INATOMI_TAHI_IMPACTOS_AMBIENTAIS.pdf>. Acesso em: 20 set. 2016.

LEITE, M. A. Impacto Ambiental das Usinas Hidrelétricas. In: SEMANA DO MEIO AMBIENTE, II, 2005, Ilha Solteira. Anais Ilhas Solteira: UNESP, 2005. 
Ramos, L. A.; Durante, L. C.; Callejas, I. J. A. Geração de Eletricidade Abordando o Ciclo de Vida: Uma Revisão Sistemática sob a Ótica da Sustentabilidade Ambiental. E\&S - Engineering and Science, (2017), 6:1.

LIMA, B. W. F. Geração Distribuída Aplicada à Edificações: Edifícios de Energia Zero e o Caso do Laboratório de Ensino da FEC-Unicamp. 2012. 149 f. Dissertação (Mestrado) Curso de Engenharia Mecânica, Faculdade de Engenharia Mecânica, Universidade Estadual de Campinas, Campinas, 2012.

MIRANDA, M. M de. Fator de Emissão de Gases de Efeito Estufa da Geração de Energia Elétrica no Brasil: Implicações da Aplicação da Avaliação de Ciclo de Vida. 2012. 162 f. Dissertação (Mestrado) - Curso de Programa de Pós-graduação em Ciências da Engenharia Ambiental, Escola de Engenharia de São Carlos, Universidade de São Paulo, São Carlos, 2012.

NOGUEIRA, L. G. Políticas e Mecanismos de Incentivo às Fontes Renováveis de Energia e o Caso Especifico da Geração Solar Fotovoltaica no Brasil e no Chile.2011. $150 \mathrm{f}$. Dissertação (Mestrado) - Curso de Planejamento de Sistemas Energéticos, Faculdade de Engenharia Mecânica, Universidade Estadual de Campinas, Campinas, 2011.

PASCALE, A; URMEE, T; MOORE, A. Life Cycle Assessment of a Community Hydroelectric Power System in Rural Thailand. Renewable Energy: An International Journal, Australia, v. 36, p.2799-2808, 2011.

PERIUS, M.R., CARREGARO, J.B. Pequenas Centrais Hidrelétricas como Forma de Redução de Impactos Ambientais e Crises Energéticas. Ensaios e Ciência. Vol. 16, No. 2, Ano 2012. Brasília 2012.

RIBEIRO, F. M.I nventario de Ciclo de Vida de Geração Hidrelétrica no Brasil -Usina de Itaipu: Primeira Aproximação. 2003. 243 f. Dissertação (Mestrado) - Curso de Programa Interunidades de Pós-graduação em Energia, Departamento de Engenharia Química, Universidade de São Paulo, São Paulo, 2003.

RIBEIRO, F. M.; A SILVA, G. Life-cycle Inventory for Hydroelectric Generation: a Brazilian Case Study. Journal of Cleaner Production, São Paulo, v. 18, p.44-54, 2010.

RUELA, A. A. Desenvolvimento Regional e as Usinas Hidrelétricas no Contexto da Última Fronteira Hidroenergética Brasileira: Uma Reflexão a Partir do Licenciamento Ambiental da UHE Teles Pires. 2016. 217 f. Tese (Doutorado) - Curso de Programa de Pósgraduação em Sociologia, Departamento de Ciências Humanas e Educação, Universidade Federal do Paraná, Curitiba, 2016.

SHAYNI, R. A.; OllVEIRA, M. A. G.; CAMARGO, I. M. T. Comparação do Custo Entre Energia Solar Fotovoltaica e Fontes Convencionais. In: Congresso Brasileiro de Planejamento Energético, V, 2006, Brasília. Anais... Brasília: UnB, 2006.

SILVA, G. G. Avaliação Ambiental dos Benefícios da Utilização da Energia Solar. 2007. 55 f. TCC (Graduação) - Curso de Engenharia Ambiental, Departamento de Engenharia, Universidade Católica de Goiás, Goiás, 2007.

SIQUEIRA, R. B. P. Emissões de Poluentes em Centrais Hidrelétricas: Aspectos Técnicos, Econômicos e Ecológicos. 2015. 141 f. Tese (Doutorado) - Curso de Transmissão e 
Conversão de Energia, Departamento de Engenharia Mecânica, Universidade Estadual Paulista, Guaratinguetá, 2015.

SUZIGAN, K. R.A Transição para uma Nova Matriz Energética Limpa: Os Avanços na Tecnologia Solar. 2015. 121 f. Dissertação (Mestrado) - Curso de Programa de Pós-graduação em Desenvolvimento Econômico, Espaço e Meio Ambiente, Instituto de Economia, Universidade Estadual de Campinas, Campinas, 2015.

TAHARA, K.; KOJIMA, T.; INABA, A. Evaluation of CO2 Payback Time of Power Plants by LCA. Energy Conversion, Tsukubalbaraki, v. 38, p.615-620, 1997.

TASSINARI, A.C. Avaliação em Emergia da Geração de Hidroeletricidade em Usinas Convencionais e Modelo Fio D'Água: Estudo de Caso. 2014. 89 f. Tese (Doutorado) - Curso de Programa de Pós-Graduação em Engenharia de Produção, Universidade Paulista, São Paulo, 2014.

TOLMASQUIM, M.T. Alternativas Energéticas Sustentáveis no Brasil. Editora Relume Dumará. Rio de Janeiro, 2004.

TSOUTSOS, T.; FRANTZESKAKI, N.; GEKAS, V. Environmental Impacts from The Solar Energy Technologies. Energy Policy. v. 33, p. 289-296, 2005.).

TURCONI, R; BOLDRIN, A; ASTRUP, T. Life Cycle Assessment (LCA) of Electricity Generation Technologies: Overview, Comparability and Limitations. Renewable and Sustainable Energy Reviews, Denmark, v. 28, p.555-565, set. 2013.

VAHL, F. P. Avaliação dos Impactos Ambientais e no Mercado: da Trajetória Tecnológica Contemporânea. 2014. 139 f. Tese (Doutorado) - Curso de Programa de Pós-graduação de Engenharia de Produção, Departamento de Engenharia de Produção, Universidade Federal de Santa Catarina, Florianópolis, 2014. 